\title{
Serviços sociais autônomos e a Administração pública brasileira
}

\author{
Christian Mendez Alcântara \\ Cirurgião-Dentista e Advogado. Mestre em Administração. Doutor em Direito.
}

\begin{abstract}
Resumo: Este trabalho tem como objetivo analisar os serviços sociais autônomos. Realizada avaliação sobre estas organizações do Estado do Paraná e do Município de Curitiba, é possível afirmar que a criação das mesmas não está inserida num contexto de reforma administrativa, estando mais vinculada a uma tentativa de maior agilidade e flexibilidade e de "fugir" da alegada rigidez do direito administrativo clássico. A utilização de termos do modelo gerencial tais como: eficiência, eficácia, agilidade, resultado e desempenho; não refletem necessariamente uma maior preocupação com melhor desempenho da Administração pública, tendo em vista que muitas vezes as metas presentes nos contratos de gestão são excessivamente genéricas. Não foram observadas avaliações consistentes de maior eficiência e eficácia. Sugere-se que os serviços sociais autônomos, quando controlados diretamente ou indiretamente pelo Estado, através de indicação da maioria de sua diretoria ou de financiamento público majoritário de suas atividades, obedeçam e sigam o direito administrativo, especialmente o procedimento licitatório, o processo seletivo público para contratação de pessoal e a prestação de contas ao Tribunal de Contas do Estado.
\end{abstract}

Palavras-chave: Serviços sociais autônomos. Eficiência. Eficácia. Avaliação.

Sumário: 1 Introdução - 2 Serviços sociais autônomos - 2.1 Serviços sociais autônomos no Estado do Paraná - 2.2 Serviços sociais autônomos em Curitiba - 3 Estudo e análise dos serviços sociais autônomos - 3.1 Paranacidade - $\mathbf{3 . 2}$ Paranaprevidência - 3.3 Ecoparaná - 3.4 Instituto Curitiba de Saúde (ICS) - 4 Considerações finais - Referências

\section{Introdução}

Este trabalho analisa os serviços sociais autônomos, originalmente do sistema " $\mathrm{S}$ " e com capacidade tributária para arrecadar contribuições parafiscais, mas que no Estado do Paraná e no Município de Curitiba adquiriram características específicas, recebendo dotações orçamentárias.

Foram avaliados os serviços sociais autônomos do Estado do Paraná e do Município de Curitiba. Examinaram-se a legislação, os estatutos, os regulamentos e os contratos de gestão. Em alguns casos, também foram realizadas entrevistas com diretores ou gerentes destas entidades.

\section{Serviços sociais autônomos}

Os serviços sociais autônomos (SSA), para Hely Lopes Meirelles, ${ }^{1}$ são entes de cooperação instituídos por lei, com personalidade de Direito

MEIRELLES. Direito administrativo brasileiro. 22. ed. 
Privado, para ministrar assistência ou ensino. São mantidos por dotações orçamentárias ou contribuições parafiscais. Apresentam administração e patrimônio próprios, seus funcionários são regulamentados pela Consolidação das Leis Trabalhistas (CLT) e devem prestar contas dos recursos públicos para sua manutenção. Seus exemplos mais conhecidos são o SENAC, o SENAI, o SESC e o SESI.

Tais entidades não prestam serviços públicos, mas atividades privadas de interesse público. Por esse motivo não são consideradas integrantes da Administração pública. Apesar disso, para Maria Sylvia Zanella Di Pietro, ${ }^{2}$ estão sujeitas a normas semelhantes a esta, tais como: observância aos princípios da licitação, processo seletivo na seleção de pessoal e prestação de contas. Entretanto, é preciso destacar que existe o entendimento do Tribunal de Contas da União ${ }^{3}$ (TCU), de que as entidades do sistema "S" — Sebrae, Senac, Senai, Sesc e Senat — não estão totalmente sujeitas aos procedimentos da Lei n ${ }^{\circ}$ 8.666/93, podendo editar regulamentos próprios licitatórios, desde que observem os princípios gerais que norteiam a execução da despesa pública, como a legalidade, a moralidade, a finalidade, a isonomia, a igualdade e a publicidade.

É interessante observar que essa decisão do Tribunal de Contas da União versa sobre a entidade "Serviço Nacional de Aprendizagem Comercial" do Estado do Rio Grande do Sul. Ou seja, uma entidade do sistema "S" que tem competência para arrecadar contribuições parafiscais e não recebe dotações orçamentárias.

Os serviços sociais autônomos fazem parte das entidades paraestatais. Não há consenso nem uniformidade terminológica sobre a definição de paraestatal. Para Hely Lopes Meirelles, ${ }^{4}$ entidades paraestatais são organizações privadas e que prestam atividades “impróprias” do Poder Público. Para ele, paraestatal não é estatal nem particular, é o meio termo entre o público e o privado. Maria Cristina Galvão ${ }^{5}$ considera os Serviços Sociais Autônomos, as Organizações Sociais e as Fundações, como sendo entidades paraestatais de cooperação.

\footnotetext{
DI PIETRO. Parcerias na administração pública: concessão, permissão, franquia, terceirização e outras formas. 4. ed., p. 221.

3 BRASIL. Tribunal de Contas da União. Decisão n 907/1997. Ministro Relator Lincoln Magalhães da Rocha. Diário Oficial da União, 26 dez. 1997.

4 MEIRELLES. Direito administrativo brasileiro. 22. ed., p. 321, 322.

5 GALVÃO (Coord.). Novas formas de gestão dos serviços públicos: a relação público-privada.
} 
Em recente decisão do Supremo Tribunal Federal, ${ }^{6}$ o termo "entes de cooperação" é usado para serviços sociais autônomos e organizações sociais. Sérgio de Andrea Ferreira $7^{7}$ usa o termo "Paradministração". Este vocábulo indica a proximidade, o tangenciamento, deste conjunto à Administração pública, sem dela pertencer. Alguns autores como Hely Lopes Meirelles $^{8}$ e Moreira Neto ${ }^{9}$ incluem no conceito de paraestatal as empresas públicas e sociedades de economia mista; outros não, como Bandeira de Mello. ${ }^{10}$ É interessante observar, entretanto, que Moreira Neto ${ }^{11}$ diferencia paraestatais integrantes da Administração indireta: empresas públicas e sociedades de economia mista; e não integrantes da Administração indireta: serviços sociais autônomos. Eros Roberto Grau ${ }^{12}$ também observa que os SSA não estão incluídos na Administração pública indireta.

Além dos serviços sociais autônomos, são consideradas paraestatais para Maria Zanella Di Pietro, ${ }^{13}$ as organizações sociais e organizações da sociedade civil de interesse público. Para a mesma autora, as organizações paraestatais são similares a entidades públicas não-estatais. Públicas, porque prestam atividade de interesse público e não estatais, porque não integram a Administração pública, direta ou indireta. Essas organizações compõem, no entendimento da autora, em conjunto com as organizações não-governamentais, o denominado terceiro setor.

O conceito de terceiro setor geralmente engloba entes privados sem fins lucrativos com participação voluntária e objetivos de interesse social e coletivo. ${ }^{14}{ }^{15}$ Para Paulo Modesto, ${ }^{16}$ o terceiro setor é constituído por pessoas privadas de fins públicos, sem finalidade lucrativa, constituídas voluntariamente por particulares, auxiliares do Estado na persecução de atividade de conteúdo social relevante. Segundo este autor, as entidades declaradas

\footnotetext{
6 BRASIL. Supremo Tribunal Federal, Agravo Regimental no Agravo de Instrumento n 349.477-1, Paraná, Relator: Ministro Celso Mello. 11 fev. 2003. DJ, 28 fev. 2003.

7 FERREIRA. Estudo jurídico sobre a natureza da Paraprevidência. Revista de Previdência Funcional, ano 1, n. 0, p. 96-121.

8 MEIRELLES. Direito administrativo brasileiro. 22. ed.

9 MOREIRA NETO. Natureza jurídica dos serviços sociais autônomos. Revista Direito Administrativo, 207, p. 83.

10 BANDEIRA DE MELLO. Curso de Direito Administrativo. 12. ed.

11 MOREIRA NETO. Natureza jurídica dos serviços sociais autônomos. Revista Direito Administrativo, 207, p. 89.

12 GRAU. Parecer Paraná Tecnologia, 2001. 21 p.

13 DI PIETRO. Direito administrativo. 14. ed.

14 ROCHA. Terceiro setor.

15 SEIXAS. As organizações sociais de saúde em São Paulo, 1998-2002: uma visão institucional. São Paulo, 2003. 192 f. Dissertação (Mestrado em Administração) - Escola de Administração de Empresas de São Paulo, Fundação Getúlio Vargas.

${ }^{16}$ MODESTO. Reforma do Estado e formas de prestação de serviços. In: SUNDFELD (Coord.). Parcerias públicoprivadas, p. 433-486.
} 
de utilidade pública, as organizações sociais, as OSCIPs e os serviços sociais autônomos fazem parte do terceiro setor.

Apesar de não ser objeto direto deste artigo e das observações de Maria Sylvia Zanella Di Pietro e Paulo Modesto, consideramos que a denominação de terceiro setor está mais próxima das organizações nãogovernamentais e das OSCIPs. Excluir-se-iam as organizações sociais e os serviços sociais autônomos, que recebem quase que exclusivamente dotações orçamentárias, pela excessiva dependência dos recursos financeiros da Administração pública.

Fernando Scaff ${ }^{17}$ diferencia os serviços sociais autônomos do Sistema "S" dos demais. Os primeiros têm capacidade tributária para arrecadar contribuições parafiscais. Os do segundo tipo, objeto deste trabalho, recebem dotações orçamentárias, como, por exemplo, os SSA paranaenses. Apesar da mesma nomenclatura, são tipos distintos.

Justen Filho ${ }^{18}$ critica os serviços sociais autônomos vinculados a entes estatais, pois, para ele, foram criados com o intuito básico de escapar ao regramento jurídico da Administração pública. A instituição somente é efetivamente autônoma, e assim designada, se não houver intervenção estatal na sua administração. Se o Estado indica os administradores, determina a orientação e o financiamento das atividades estratégicas, a organização deve ser controlada como componente da Administração pública, aplicando o regime de licitação e de contratação administrativas.

Em caso específico, Maria Sylvia Zanella Di Pietro ${ }^{19}$ cita o caso da "Associação das Pioneiras Sociais", serviço social autônomo criado pela Lei Federal $n^{\circ} 8.246 / 91$. Tece uma série de críticas a ela, pois é uma associação sem associados, vive de dotação orçamentária da União, está sob controle do Ministério da Saúde e na lei que a instituiu há previsão de procedimento próprio de licitação. Considera que a Associação de Pioneiras Sociais está em situação totalmente irregular, tem uma série de características de entidades da Administração indireta e um de seus objetivos é tentar fugir do regime jurídico publicístico.

Em sentido oposto a Justen Filho e a Di Pietro, Moreira Neto ${ }^{20}$ considera que os serviços sociais autônomos não devem se submeter ao

17 SCAFF. Contrato de gestão, serviços sociais autônomos e intervenção do Estado. Revista Direito Administrativo, 225, p. 273-297.

18 JUSTEN FILHO. Comentários à lei de licitações e contratos administrativos. 10. ed., p. 32.

19 DI PIETRO. Parcerias na administração pública: concessão, permissão, franquia, terceirização e outras formas. 4. ed., p. 222 et seq.

20 MOREIRA NETO. Natureza jurídica dos serviços sociais autônomos. Revista Direito Administrativo, 207, p. 94. 
controle do direito administrativo. Considera-o antiquado e fruto de inércia burocrática. Concordamos com o posicionamento de Marçal Justen Filho e de Maria Sylvia Zanella Di Pietro.

Os serviços sociais autônomos do sistema " $\mathrm{S}$ " que arrecadam contribuições parafiscais já apresentam algumas décadas no Brasil e têm uma função geralmente bem definida. Por outro lado, os SSA que recebem dotações orçamentárias são mais recentes e dependem basicamente da Administração pública. Neste caso, sugere-se, tal como Marçal Justen e Maria Zanella Di Pietro, quando utilizados recursos públicos, a aplicação da legislação administrativa. Considera-se também inadequado, tal como Marçal Justen, o termo "autônomo" para uma organização que depende quase que exclusivamente de recursos públicos. Neste caso, recomenda-se a alteração da nomenclatura.

\subsection{Serviços sociais autônomos no Estado do Paraná}

No Estado do Paraná, durante os anos 1995-2002, foram criados serviços sociais autônomos buscando mais agilidade e eficiência, repetindo os pressupostos do modelo gerencial. É interessante observar que a criação de alguns serviços sociais autônomos, como Paranacidade, Paranatecnologia e o Paranaeducação, os dois últimos já extintos, os quais não serão analisados neste artigo, ocorreu antes mesmo da Emenda Constitucional no 19 de 1998.

A proposta do Governo Jaime Lerner pode ser sintetizada pelo então Secretário de Administração Ricardo Smijtink. Para este, parafraseando David Osborne, em entrevista ao jornal Gazeta do Povo, o Estado não é um bom prestador de serviço, e o que ele precisa fazer é garantir que o serviço seja oferecido. ${ }^{21}$ Essa afirmação explica, em parte, a forma que o Governo Jaime Lerner deu a suas mudanças administrativas, que parecem basicamente ter como objetivos a delegação de atividades públicas para entidades privadas e a fuga da alegada rigidez e lentidão do direito administrativo.

As modificações administrativas de Jaime Lerner deram-se, principalmente, mediante a criação de serviços sociais autônomos: Paranaprevidência, Paranacidade, Ecoparaná, Paraná Tecnologia e Paranaeducação; os dois últimos já extintos. Nas leis estaduais paranaenses que estabelecem esses Serviços Sociais são comuns artigos que prevêem processos licitatórios simplificados e maior eficiência na utilização de recursos públicos.

\footnotetext{
${ }^{21}$ GALINDO. Governo Lerner gasta $94 \%$ a mais para manter 25 mil cargos a menos. Gazeta do Povo, Curitiba, p. 3, 6 maio 2002.
} 
Quanto à fiscalização desses serviços sociais autônomos, houve decisão unânime do Tribunal de Contas do Estado do Paraná (TCE-PR) da obrigatoriedade dos Serviços Sociais Autônomos de prestarem contas dos seus exercícios financeiros. ${ }^{22}$ É importante observar que no ano seguinte a esta decisão, foi aprovada a Lei estadual $n^{\circ} 12.966 / 2000^{23}$ estabelecendo que as contas dos SSA: Paranacidade, Paranaeducação e Ecoparaná são analisadas pela Assembléia Legislativa, com o auxílio do Tribunal de Contas do Estado. No Paranaprevidência o controle do TCE-PR está estabelecido no artigo $7^{\circ}$, inciso IV, da Lei $\mathrm{n}^{\circ}$ 12.398/98.

Algumas das alterações do Governo Jaime Lerner foram paralisadas ou revertidas no Governo Roberto Requião, que se iniciou em janeiro de 2003. Ocorreu, por exemplo, anulação do contrato de gestão do Estado do Paraná com o Paranátecnologia, e foi aprovada a Lei Estadual no 15.123/ $2006,{ }^{24}$ que faz alterações na Lei Estadual no 12.020/98, estabelecendo o retorno do gerenciamento do Fundo Paraná para a Secretaria Estadual de Ciência Tecnologia.

\subsection{Serviços sociais autônomos em Curitiba}

No ano de 1999 em Curitiba foi criado através da Lei Municipal $n^{\text {o }} 9.626 / 99^{25}$ o serviço social autônomo - Instituto Curitiba de Saúde (ICS), com personalidade jurídica de direito privado. No mesmo município há também Lei Municipal no 9.226/97 que autoriza o Poder Executivo a qualificar pessoas jurídicas de direito privado sem fins lucrativos como organizações sociais. Essa lei foi uma das primeiras do Brasil e apresenta grande similaridade com a lei federal. No momento da redação deste artigo, há duas organizações sociais em Curitiba, o Instituto Curitiba de Informática e o Instituto Curitiba de Arte e Cidadania, os quais não serão objeto de análise neste trabalho.

\footnotetext{
22 PARANÁ. Tribunal de Contas. Resolução n 7150/99. Relator: Rafael latauro. $1^{\circ}$ set. 1999.

23 PARANÁ. Lei no 12.966 , de 25 de outubro de 2000 . Altera a redação dos dispositivos que especifica, das Leis $n^{\circ}$ s 11.498/96, 11.970/97 e 12.215/98, através das quais foram instituídos, respectivamente, o PARANACIDADE, PARANAEDUCAÇÃO e ECOPARANÁ.

24 PARANÁ. Lei n 15.123 , de 18 de maio de 2006. Dá nova redação nos dispositivos que específica da Lei 12.020 de 09 de janeiro de 1998, que criou o FUNDO PARANÁ.

${ }^{25}$ CURITIBA. Lei n 9626 de 8 de julho de 1999. Dispõe sobre o Sistema de Seguridade Social dos Servidores do Município de Curitiba, altera a denominação e modifica a estrutura e atribuições do Instituto de Previdência e Assistência dos Servidores do Município de Curitiba - IPMC, e dá outras providências.
} 


\section{Estudo e análise dos serviços sociais autônomos}

\subsection{Paranacidade}

O Paranacidade, serviço social autônomo, foi criado mediante a Lei Estadual $n^{\circ} 11.498$ em 30 de julho de 1996, ${ }^{26}$ alterada pelas Leis Estaduais $\mathrm{n}^{\circ} 12.651$, de 23 de julho de $1999,{ }^{27} \mathrm{e} \mathrm{n}^{\mathrm{o}} 12.966$, de 25 de outubro de $2000 .^{28}$ A Lei $n^{\circ}$ 12.966/2000 estabeleceu que as contas do Paranacidade, bem como do Paranaeducação e Ecoparaná, serão julgadas pela Assembléia Legislativa, com o auxílio do Tribunal de Contas do Estado, reafirmando posicionamento anterior do Plenário deste Tribunal, já comentado anteriormente neste trabalho.

Este serviço social autônomo substituiu a autarquia "Instituto de Assistência aos Municípios do Paraná” (FAMEPAR) e os bens móveis e imóveis desta foram repassados ao Paranacidade (art. 22 da Lei $n^{\circ} 11498 / 96$ ). Entre outras funções, esta entidade presta assistência técnica aos municípios, capta e aplica recursos no desenvolvimento urbano e regional do Estado do Paraná e gerencia o Fundo Estadual de Desenvolvimento Urbano, instituído pela Lei Estadual no 8.917, de 15 de dezembro de 1988. ${ }^{29}$ No artigo $2^{\text {o30 }}$ há previsão estabelecendo sua composição.

O Paranacidade é vinculado, por cooperação, à Secretaria de Estado do Desenvolvimento Urbano (SEDU) e seu superintendente é o Secretário desta pasta (art. $2^{\circ}$, da Lei $\left.\mathrm{n}^{\circ} 11.498 / 96\right)$.

${ }^{26}$ PARANÁ. Lei no 11.498, de 30 de julho de 1996. Institui o PARANACIDADE, pessoa jurídica de direito privado e adota outras providências.

27 PARANÁ. Lei n 12.651, de 23 de julho de 1999. Altera os dispositivos que especifica da Lei n 11498 , de 30 de julho de 1996, que institui o PARANACIDADE.

28 PARANÁ. Lei n 12.966, de 25 de outubro de 2000. Altera a redação dos dispositivos que especifica, das Leis $n^{\circ}$ s 11.498/96, 11.970/97 e 12.215/98, através das quais foram instituídos, respectivamente, o PARANACIDADE, PARANAEDUCAÇÃO e ECOPARANÁ.

${ }^{29}$ PARANÁ. Lei no 8.917, de 15 de dezembro de 1988. Institui o Fundo Estadual de Desenvolvimento Urbano e adota outras providências.

30 Art. $2^{\circ}$ - O FDU será constituído:

I - Pelo retorno dos sub-empréstimos do programa de Ação Municipal - PrAM, contratados pelo Banco do Estado do Paraná S.A., junto às municipalidades paranaenses;

II - Pelos rendimentos provenientes da aplicação dos recursos do FDU no mercado financeiro;

III - Pelo produto resultante de juros e amortizações da aplicação dos recursos do FDU;

IV - Pelo produto resultante de operações de crédito interno e externo, integralizado para financiar intervenções representadas por planos, programas, projetos e atividades voltadas ao Desenvolvimento Urbano;

$\checkmark$ - Pelo aporte de recursos municipais;

VI - Pelo aporte de recursos ordinários do Tesouro do Estado;

VII - Pelo aporte de recursos do Governo Federal;

VIII - Pelo retorno de empréstimos contratados pelo Governo do Estado e repassados aos municípios paranaenses, em intervenções voltadas ao Desenvolvimento Urbano;

IX - Pelos recursos provenientes de ajuda e cooperação internacional e acordos bilaterais entre governos;

$X$ - Pelo produto decorrente de acordos, convênios e contratos;

$\mathrm{XI}$ - de outras receitas eventuais. 
O contrato de gestão celebrado entre o Paranacidade e o Estado do Paraná tem a previsão de prazo de vinte anos (art. $15, \S^{\circ}$, da Lei ${ }^{\circ}$ 11.498/96, e cláusula sétima do contrato de gestão). ${ }^{31}$ Foi assinado pelo então Governador do Estado do Paraná e o Superintendente do Paranacidade com interveniência das Secretarias de Fazenda e a do Desenvolvimento Urbano (art. 15, $\S 1^{\circ}$ da Lei $\left.\mathrm{n}^{\circ} 11498 / 96\right)$.

Fernando Scaff $^{32}$ constata que a mesma pessoa física assina como contratante (Secretário de Estado de Desenvolvimento Urbano) e como contratado (Superintendente do Paranacidade) e aponta possível nulidade:

Sobre este contrato, aliás, deve-se registrar um fato extremamente curioso, que deve inegavelmente acarretar sua nulidade por vício formal: uma mesma pessoa física firmou por três das partes envolvidas: na qualidade de Superintendente do Paranacidade, de Secretário de Estado e Desenvolvimento Urbano e de Secretario de Estado do Planejamento e Coordenação Geral. Ou seja, assinou como interveniente contratante e como contratado.

No artigo 15, inciso II, da Lei $\mathrm{n}^{\circ} 11.498 / 96$ está estabelecido que a contratação de recursos humanos se dá pela Consolidação das Leis do Trabalho (CLT). Observa-se que no parágrafo único do artigo $9^{\circ}$ do Estatuto está prevista a admissão em cargo de carreira de provimento permanente no Paranacidade mediante seleção competitiva pública. ${ }^{33}$

Segundo o relatório da Comissão ParIamentar de Inquérito(CPI) SEDU/Paranacidade ${ }^{34}$ no período de 1995 a 2002, os empregados do Paranacidade foram admitidos mediante simples entrevista e análise eventual de títulos. No ano de 2002, este serviço social autônomo contava com 105 funcionários.

Antonio Toledo da Silva, ${ }^{35}$ Diretor de Administração e Finanças deste serviço social autônomo, informou que este serviço social autônomo apresenta atualmente cerca de 120 funcionários celetistas e, destes, aproximadamente 20 eram servidores estatutários e optaram pelo Paranacidade no ano de 1996. Registra também que desde 2003 foram contratadas

\footnotetext{
31 PARANÁ. Contrato de gestão que entre si celebram o Estado do Paraná e o Serviço Social Autônomo PARANACIDADE, Curitiba, 23 out. 1996.

32 SCAFF. Contrato de gestão, serviços sociais autônomos e intervenção do Estado. Revista Direito Administrativo, 225, p. 273-297.

33 PARANÁ. Estatuto do Serviço Social Autônomo PARANACIDADE. Publicado em DOE, n. 5.631, p. 14, 2 dez. 1999.

34 PARANÁ. CPI SEDU/PARANACIDADE - Relatório Final. 10 nov. 2003. p. 14.

35 SILVA. Comunicação pessoal.
} 
nove pessoas; entretanto, reconhece que a legalidade do processo de escolha destes funcionários está sendo questionada pelo Tribunal de Contas do Estado.

No inciso III do mesmo artigo 15 (Lei n $\left.{ }^{\circ} 11.498 / 96\right)$ estão previstos processos licitatórios simplificados, bem como na alínea "f”, da cláusula quarta do contrato de gestão. Segundo o relatório da Comissão Parlamentar de Inquérito (CPI) SEDU/Paranacidade, ${ }^{36}$ este serviço social autônomo apresentava regulamento próprio de licitações, cujo valor de dispensa de licitação para obras, serviços e compras era de até trinta mil reais. Para esta mesma CPI ${ }^{37}$ houve inúmeras dispensas de licitações, fundamentadas em notória especialização.

... fundamentados na notória especialização do contratado, o que, de acordo com o histórico de ação do PARANACIDADE, significava tão somente que este era amigo ou indicado por pessoa influente no processo.

Segundo Antonio Toledo Silva, ${ }^{38}$ o regulamento próprio de licitações do Paranacidade não é utilizado desde 2003, sendo aplicado desde então a Lei ${ }^{\circ} 8.666 / 93$.

É no Estatuto do Paranacidade ${ }^{39}$ que foi explicitada a terminologia do modelo gerencial e está prevista nos artigos quarto e quinto:

Art. $4^{\circ}$ - O PARANACIDADE, na consecução de sua missão institucional e de seus objetivos, balizar-se-á pelas seguintes diretrizes:

II. implementar ações de excelência, maximizando a eficiência e a eficácia na busca de resultados, capacitando-se como Entidade de referência em assuntos ligados à captação de recursos destinados aos planos, programas e projetos de desenvolvimento urbano e regional.

...

VII. criar e implementar sistema eficiente de relacionamento e de articulação com entidades análogas no País, no exterior e com organismos estrangeiros e internacionais voltados para estudos e pesquisas de desenvolvimento urbano e regional.

Art. $5^{\circ}$ - O PARANACIDADE tem por objetivos:

\footnotetext{
36 PARANÁ. CPI SEDU/PARANACIDADE - Relatório Final. 10 nov. 2003. p. 22, 119.

37 PARANÁ. CPI SEDU/PARANACIDADE - Relatório Final. 10 nov. 2003. p. 27, 159, 165.

38 SILVA. Comunicação pessoal.

39 PARANÁ. Estatuto do Serviço Social Autônomo - PARANACIDADE. DOE, n. 5.631, p. 14, 2 dez. 1999.
} 
V. contribuir para a eficiente aplicação dos recursos públicos, tanto federais como estaduais e municipais,... (sem grifo no original).

É importante observar que no contrato de gestão entre o PARANACIDADE e o Estado do Paraná está estabelecida, na cláusula nona, a avaliação de resultados. Entretanto, no nosso entendimento, ela é excessivamente genérica e não explicita de que forma se dão a busca e a avaliação da eficiência e da eficácia deste serviço social autônomo.

Cláusula nona

Da avaliação dos resultados

PARANACIDADE promoverá, de forma sistemática e constante, a avaliação do desempenho e dos resultados de suas ações e atividades, com vistas à efetividade de cumprimento de sua missão, compromissos, diretrizes e objetivos e à produção do relatório anual e da prestação de contas a serem apresentados à Assembléia Legislativa do Estado do Paraná, conforme Artigo 16 da Lei 11.498 de 30 de julho de 1996. (sem grifo no original)

Para Antonio Toledo da Silva, ${ }^{40}$ apesar de ainda não existir uma avaliação sistemática de resultados e cumprimento de metas, há preocupação crescente com eficiência e eficácia neste serviço social autônomo. Considera também que a própria orientação do Tribunal de Contas do Estado tem priorizado, além das questões formais, a consecução de metas e resultados.

Fernando Scaff $^{41}$ ressalta que o Paranacidade passou a exercer funções muito semelhantes à organização a que substituiu, a autarquia FAMEPAR, dependendo basicamente de recursos orçamentários para o desenvolvimento de suas atividades.

É importante registrar que em 2003 foi instaurada Comissão Parlamentar de Inquérito (CPI) na Assembléia Legislativa do Paraná, com o objetivo de investigar eventuais irregularidades neste serviço social autônomo nos anos de 1996 a 2002. ${ }^{42}$

O relatório ${ }^{43}$ desta Comissão Parlamentar de Inquérito, apresentado pelo então Deputado José Maria Ferreira e aprovado pelo Plenário da Assembléia Legislativa, apontou diversas irregularidades na aplicação de recursos públicos. Ocorreram gastos de 2,5 milhões de reais com cursos de especialização, mestrado e doutorado, no Brasil e no exterior, e 410 mil reais em cursos de línguas estrangeiras no período auditado, entre outras despesas

\footnotetext{
40 SILVA. Comunicação pessoal.

${ }^{41}$ SCAFF. Contrato de gestão, serviços sociais autônomos e intervenção do Estado. Revista Direito Administrativo, 225, p. 273-297.

42 DONATTI. Informe Folha: paranacidade. Folha de Londrina, p. 3, 20 nov. 2003.

43 PARANÁ. CPI SEDU/PARANACIDADE - Relatório Final. 10 nov. 2003. p. 16, 17.
} 
que não apresentam relação direta com os objetivos do Paranacidade. Somente um curso de mestrado para um funcionário na Itália custou 37 mil dólares. A publicação de um livro sobre obras de artistas paranaenses custou 350 mil reais. ${ }^{44}$

O relatório na sua conclusão ${ }^{45}$ ressalta a necessidade de rever a estrutura jurídica desta entidade:

A confusão criada pelo fato de se querer instituir um novo modelo administrativo, liberando-se da pretensa burocracia existente na Administração Pública - (...) - produziu circunstâncias deploráveis, denotativas da falta de empenho no atendimento dos princípios da economicidade, da eficácia e da efetividade e, por que não citar, do conceito tão apregoado pelos consultores do BID e por este mesmo, de accountability.

Outros exemplos de ações irregulares no Paranacidade podem ser apontados na contratação do filho de um membro do primeiro escalão de governo e do pai de outro, sendo que em ambos os casos, os contratos foram procedidos com dispensa de licitação, para serviços cujas circunstâncias são de todo duvidosas.

Antonio Toledo da Silva, ${ }^{46}$ diretor do Paranacidade, reconhece os problemas no período investigado. Frisa que o Governador, ao iniciar o mandato em 2003, pretendia extinguir este serviço social autônomo. Segundo este mesmo diretor, o Paranacidade demonstrou competência técnica e agilidade, chegando, inclusive a auxiliar outras Secretarias de Estado, como a da Saúde e a da Educação.

Na mensagem $n^{0}$ 013/06 do Projeto de Lei $n^{\circ}$ 060/2006, ${ }^{47}$ o atual Governador do Estado reconhece algumas distorções apontadas pelo Tribunal de Contas do Estado, pela Procuradoria Geral do Estado, pelo Ministério Público, bem como pela Comissão Parlamentar de Inquérito da Assembléia Legislativa. Entretanto, no parágrafo seguinte ressalta que este serviço social autônomo é consultor modelo e referência mundial do Banco Interamericano de Desenvolvimento (BID).

Inúmeras questões de natureza institucional foram levantadas pelos agentes externos a ele relacionado, em especial a Procuradoria Geral do Estado - PGE,

\footnotetext{
44 PARANÁ. CPI SEDU/PARANACIDADE - Relatório Final. 10 nov. 2003. p. 37.

45 PARANÁ. CPI SEDU/PARANACIDADE - Relatório Final. 10 nov. 2003. p. 222.

46 SILVA. Comunicação pessoal, 2006.

47 PARANÁ. Projeto de Lei $n^{\circ}$ 060/2006 (Mensagem nº 013/06). Institui o Serviço Social Autônomo PARANACIDADE e convalida os atos praticados com base na Lei Estadual n 11.498, de 30.07.1996 alterada pelas Leis Estaduais nº 12.651, de 23.09.1999, 12.966, de 25.10.2000 e 14.045, de 05.05.2003.
} 
o Tribunal de Contas do Estado - TCE, o Ministério Público - MP e essa Casa de Leis, através da Comissão Parlamentar de Inquérito - CPI, instituída em 17.03.2003, sendo imperiosa a aprovação da presente Lei Estadual para a correção das distorções apontadas na atuação da entidade no Estado do Paraná.

Por outra parte, não há como deixar de reconhecer a importância da Entidade no cenário estadual e por que não dizer mundial..

Produzindo e desenvolvendo uma expertise que se tornou referência para outros Estados e Nações que contratam o BID a ponto de ser indicada como consultora modelo...

As finalidades do Paranacidade, para o relatório final da Comissão Parlamentar de Inquérito deste serviço social autônomo, são incompatíveis com o perfil definido pela doutrina sobre estas entidades. Ou seja, este serviço social autônomo continua exercendo atividades tipicamente públicas, anteriormente exercidas por uma autarquia, depende basicamente de recursos públicos, estando subordinado à Secretaria de Desenvolvimento Urbano (SEDU) do Estado do Paraná.

Entendemos que se mantendo o Paranacidade como serviço social autônomo ele deve observar os princípios da Administração pública, bem como o procedimento licitatório, o concurso público ou teste seletivo público para contratação de pessoal e prestação de contas ao Tribunal de Contas do Estado.

O Estatuto do Paranacidade reflete o ideário gerencial: eficiência, eficácia e resultados; entretanto, não foi possível constatar uma avaliação sistematizada, isto, inclusive reconhecido pelo diretor entrevistado deste serviço social autônomo.

\subsection{Paranaprevidência}

Instituído pela Lei Estadual $\mathrm{n}^{\circ} 12.398 / 98,{ }^{48}$ a Paranaprevidência inicialmente compreendia os Programas de Previdência e de Serviços Médico-Hospitalares. A adesão dos servidores a ele era obrigatória e esta foi questionada por inúmeras ações judiciais. ${ }^{49}$ Ocorreu, então, a separação da Previdência, neste momento função desempenhada pela Paranaprevidência, e a dos Serviços Médicos-Hospitalares, que foram prestados pelo Instituto de Previdência e Assistência aos Servidores do Estado do

\footnotetext{
48 PARANÁ. Lei no 12.398, de 30 de dezembro de 1998. Cria o Sistema de Seguridade Funcional do Estado do Paraná, transforma o Instituto de Previdência e Assistência aos Servidores do Estado do Paraná — IPE em Serviço Social Autônomo, denominado PARANAPREVIDÊNCIA, e dá outras providências.

49 PARANÁ. Projeto de Lei Estadual n 02/2001 (Justificativa). Institui o Sistema de Assistência à Saúde aos servidores públicos ativos e inativos do Estado do PR.
} 
Paraná (IPE) até o dia 29 de maio de 2002. A partir desta data, esses serviços vêm sendo prestados através do Sistema de Assistência à Saúde (SAS).

$\mathrm{O}$ artigo $2^{\circ}$ da Lei Estadual $n^{\circ}$ 12.398/98 estabeleceu que o Instituto de Previdência e Assistência aos Servidores do Estado do Paraná (IPE) é transformado em instituição sem fins lucrativos, com personalidade jurídica de direito privado, de natureza de serviço social autônomo paraadministrativo, denominada Paranaprevidência.

Nos artigos $4^{\circ}$ e $5^{\circ}$ da mesma Lei, está estabelecido que este serviço social autônomo terá duração indeterminada e será vinculado por cooperação ao Estado do Paraná mediante contrato de gestão. Tal contrato terá por finalidades (art. $6^{\circ}$ da Lei Estadual $\left.n^{\circ} 12.398 / 98\right)$ :

a)...

b) fixar metas; (sem grifo no original)

c) estabelecer, de modo objetivo, as responsabilidades pela execução e pelos prazos referentes aos planos, programas, projetos e atividades a cargo da PARANAPREVIDÊNCIA;

d) avaliar desempenho, com aferição de sua eficiência e da observância dos princípios da legalidade, legitimidade, moralidade, razoabilidade, proporcionalidade, impessoalidade, economicidade e publicidade, e atendimento aos preceitos constitucionais, legais, regulamentares, estatutários e regimentais aplicáveis; (sem grifo no original)

e) preceituar parâmetros para a contratação, gestão e dispensa de pessoal, sob o regime trabalhista,...

f)...

As palavras ressaltadas anteriormente: metas, eficiência, economicidade; retratam o modelo gerencial de Administração pública. No termo aditivo ao contrato de gestão ${ }^{50}$ em sua cláusula sexta também está previsto o princípio da eficiência.

Observa-se que na alínea "e" desse artigo está estabelecido que a contratação de pessoal se dá pelo regime da CLT, também estando previsto no contrato de gestão no parágrafo $1^{\circ}$, da cláusula nona: ${ }^{51}$ "O regime jurídico do pessoal da Instituição será o trabalhista”.

Os parágrafos $8^{\circ}$ e $9^{\circ}$ estabelecem que a cessão de servidores públicos não poderá ser superior a dois anos e nem poderá exceder a $5 \%$ do quadro

50 PARANÁ. Termo aditivo ao contrato de gestão celebrado entre o Estado do Paraná e a PARANAPREVIDÊNCIA. Diário Oficial do Estado, Curitiba, 29 ago. 2002.

51 PARANÁ. Termo de contrato de gestão que celebram o Estado do Paraná e a PARANAPREVIDÊNCIA, Curitiba, 27 maio 1999. 
de pessoal da Paranaprevidência. No termo aditivo ao contrato de gestão, ${ }^{52}$ cláusula sétima, constava o limite de 31 de dezembro de 2002 para cessão de servidores públicos à Paranaprevidência.

Essas cláusulas de limitação de cessão de pessoal e de tempo são importantes, pois criam dificuldades na mera transposição de entidades públicas para organizações privadas, em alguns casos visando basicamente "fugir" às exigências do regime de direito administrativo: concursos públicos, licitações e prestação de contas, por exemplo.

No artigo $7^{\circ}$, inciso IV, ${ }^{53}$ da Lei $\mathrm{n}^{\circ} 12.398 / 98$ está estabelecido o encaminhamento das contas do Paranaprevidência ao Tribunal de Contas do Estado.

No contrato de gestão, ${ }^{54}$ em sua cláusula décima sétima, estão previstas uma série de metas de implantação e seus respectivos prazos. Entretanto, elas se referem mais à consolidação da organização Paranaprevidência do que efetivamente à mensuração de padrões de eficiência e eficácia na prestação de serviços previdenciários aos servidores públicos estaduais do Paraná. Na cláusula $2^{\mathrm{a}}$ e seus incisos I e II do termo aditivo $^{55}$ estão previstas como metas permanentes:

I - Na gestão geral do Sistema de Seguridade Funcional:

a) proporcionar tratamento criterioso e personalizado aos inscritos no Sistema;

b) implantar e manter procedimentos ágeis e rotinas desburocratizadas...

c) monitorar rigorosamente...

$\cdots$

II - Na gestão do Programa de Previdência:

a) executar adequadamente o Plano de Benefícios...

Tais metas denominadas permanentes, em que são utilizados adjetivos como "criterioso", "ágeis", "rigorosamente" e "adequadamente", são praticamente impossíveis de serem avaliadas e parece mais um recurso discursivo do que efetivamente preocupação com eficiência ou eficácia.

52 PARANÁ. Termo aditivo ao contrato de gestão celebrado entre o Estado do Paraná e a PARANAPREVIDÊNCIA. Diário Oficial do Estado, Curitiba, 29 ago. 2002.

53 IV - Encaminhar as contas anuais da Instituição ao Tribunal de Contas do Estado, acompanhadas dos pareceres do Conselho Fiscal, da Consultoria Atuarial e da Auditoria Externa Independente, bem como da deliberação, a respeito, do Conselho de Administração.

54 PARANÁ. Termo de contrato de gestão que celebram o Estado do Paraná e a PARANAPREVIDÊNCIA, Curitiba, 27 maio 1999.

55 PARANÁ. Termo aditivo ao contrato de gestão celebrado entre o Estado do Paraná e a PARANAPREVIDÊNCIA. Diário Oficial do Estado, Curitiba, 29 ago. 2002. 
Uma das maiores críticas especificamente à Paranaprevidência é a de que sua natureza jurídica de serviço social autônomo seria inadequada. Por gerir o sistema previdenciário dos servidores públicos estaduais do Paraná e suas receitas serem oriundas também do Estado (conforme artigo 83 da Lei Estadual $\left.n^{o} 12.398 / 98\right),{ }^{56}$ sua figura administrativa mais apropriada seria o de autarquia, aliás como era o extinto IPE. Neste sentido é o parecer de Angela Cassia Costaldello ${ }^{57}$ em resposta à consulta formulada pelo Conselho de Administração da Paranaprevidência. Neste mesmo parecer há orientação de que os funcionários estão submetidos ao teto remuneratório previsto na Constituição Federal, artigo 37, inciso XI, bem como a contratação dos mesmos deve dar-se por meio de concurso público.

Como fator positivo, é importante registrar que a Paranaprevidência observa a Lei de Licitações.

1- As compras e contratações da ParanaPrevidência se pautam pela Lei $\mathrm{n}^{\circ}$ 8.666/93, que instituiu normas para licitações e contratos da Administração Pública. ${ }^{58}$

O Paranaprevidência na lei que o institui e em seu contrato de gestão apresenta uma série de elementos da abordagem gerencial: avaliação de desempenho, metas, eficiência e economicidade. Entretanto, isso, por si só, não garante maior eficiência que o sistema anterior, o qual era gerido por uma autarquia. Aliás, as metas estabelecidas no contrato de gestão, geralmente adjetivos como "criterioso", "ágil" e "adequadamente", são praticamente impossíveis de serem avaliadas.

Consideramos importante que a Paranaprevidência continue seguindo a Lei de Licitações $n^{\circ} 8.666 / 93$ na compra de produtos, serviços e obras, prestando contas ao Tribunal de Contas do Estado, e adote o concurso ou teste seletivo público para a contratação de pessoal, conforme orientação de Ângela Costaldello, bem como deste Tribunal, estabelecida pela Resolução no 946/02.59

\footnotetext{
${ }^{56}$ Art. 83. A contribuição mensal do Estado para o FUNDO DE PREVIDÊNCIA dar-se-á nas seguintes proporções: I - 10\% (dez por cento) sobre a parcela da remuneração, proventos, subsídio ou pensão que for menor ou igual a $\mathrm{R} \$ 1.200,00$ (hum mil e duzentos reais);

II - 14\% (quatorze por cento) sobre a parcela da remuneração, proventos, subsídio ou pensão que for superior a $\mathrm{R} \$ 1.200,00$ (hum mil e duzentos reais).

57 COSTALDELLO. Parecer $n^{\circ} 14349 / 00$. Protocolo n 83007/00. Tribunal de Contas do Estado do Paraná, 2002.

58 PARANÁ. PARANAPREVIDÊNCIA. Disponível em: <http://www.paranaprevidencia.pr.gov.br>. Acesso em: 16 maio 2006.

59 PARANÁ. Tribunal de Contas. Resolução 946/02. Relator: Heinz Georg Herwig. 02 maio 2002.
} 


\subsection{Ecoparaná}

Este serviço social autônomo foi instituído pela Lei Estadual $n^{\circ}$ $12.215 / 98{ }^{60}$ Tem a finalidade de planejamento, a promoção e o gerenciamento de projetos e ações relacionados ao turismo, com ênfase ao turismo ecológico $\left(\operatorname{art} .1^{\circ}\right)$ e está vinculado à Secretaria de Estado do Esporte e Turismo $\left(\operatorname{art} .3^{\circ}\right)$.

Tal como os serviços sociais autônomos anteriores, o Ecoparaná está autorizado a firmar contrato de gestão, cujo prazo é de 20 anos, com o Poder Executivo Estadual (art. $9^{\circ}$, parágrafo $6^{\circ}$, da Lei ${ }^{\circ}{ }^{12.215 / 98)}$. Este contrato, com prazo indeterminado (cláusula oitava), foi firmado no dia 17 de setembro de 1998 pelo Governador de Estado, pelos Secretários de Estado do Esporte e Turismo e da Fazenda e pelo Superintendente do Ecoparaná. Na cláusula segunda estão estabelecidos metas e "objetivos estratégicos" como:

a) implementar ações que assegurem o fomento e desenvolvimento do turismo,...

b) implantar programas e projetos de estímulo à atividade econômica, em especial, ao turismo em áreas naturais.

Na cláusula terceira está previsto que o Ecoparaná é obrigado a cumprir as metas estabelecidas na cláusula segunda.

Também estão previstos procedimentos licitatórios simplificados (art. $9^{\circ}$, III, da Lei ${ }^{\circ}$ 12.215/98) e a contratação de recursos humanos pela Consolidação das Leis do Trabalho (art. $9^{\circ}$, II, da Lei ${ }^{\circ}$ 12.215/98). Segundo Caroline Lopes Santos, ${ }^{61}$ assessora jurídica deste serviço social autônomo, desde 2003 o Ecoparaná segue a Lei no 8.666/93, não utilizando o regulamento próprio de licitação. A mesma assessora informou que em 2006 havia 13 funcionários celetistas neste SSA, os quais foram contratados sem concurso ou processo seletivo público. Apesar da possibilidade de cessão (cláusula quinta), não havia servidores públicos cedidos ao Ecoparaná.

As contas do Ecoparaná são julgadas pela Assembléia Legislativa, com o auxílio do Tribunal de Contas do Estado (artigo 13 da Lei n ${ }^{\circ}$ 12.215/98, modificado pela Lei $\mathrm{n}^{\mathrm{O}}$ 12.966/2000).

60 PARANÁ. Lei no 12.215, de 10 de julho de 1998. Institui o ECOPARANA, pessoa jurídica de direito privado, sob a modalidade de serviço social autônomo, vinculando-a por cooperação, à Secretaria de Estado do Esporte e do Turismo - SEET.

61 SANTOS. Comunicação pessoal. 
Neste serviço social autônomo estão presentes metas e "objetivos estratégicos" que consistem basicamente em implantar ou implementar ações e programas. Não foi observada no contrato de gestão alguma cláusula estabelecendo avaliação de resultados ou consecução de metas e objetivos.

O Ecoparaná é uma organização de menor porte comparado a outros serviços sociais autônomos no Estado do Paraná. Sugere-se que nas novas contratações deste serviço social autônomo sejam feitas através de concurso ou teste seletivo público.

\subsection{Instituto Curitiba de Saúde (ICS)}

O Instituto Curitiba de Saúde é serviço social autônomo, com personalidade jurídica de direito privado, e foi criado pela Lei Municipal $n^{\circ} 9.626 / 99^{62}$ com a seguinte redação estabelecida no artigo 44 .

Art. 44. Fica criado o ICS - Instituto Curitiba de Saúde, com personalidade jurídica de direito privado, sem fins lucrativos, serviço social autônomo para estatal, vinculado, como entidade de cooperação governamental, à Secretaria Municipal de Recursos Humanos.

Posteriormente, este artigo foi alterado pela Lei Municipal $n^{\circ}$ 9.712/9963 e ficou com a seguinte redação:

Art. 50. O "caput" do art. 44 da lei no 9.626, de 08 de julho de 1999, passa a vigorar com a seguinte redação:

"Art. 44. Fica criado o Instituto Curitiba - ICS sob a forma de serviço social autônomo, com personalidade jurídica de direito privado, sem fins lucrativos, vinculado por cooperação à Secretaria Municipal de Recursos Humanos”.

O artigo 46, da Lei n ${ }^{\circ}$ 9626/99, estabelece que o Instituto Curitiba de Saúde celebrará contrato de gestão com o Município de Curitiba, cabendo a supervisão à Secretaria Municipal de Recursos Humanos. No objeto deste contrato, estarão presentes a fixação de metas e a avaliação de desempenho da Entidade, com aferição de sua eficiência (art. 46, parágrafo único,

${ }^{62}$ CURITIBA. Lei n 9626 de 8 de julho de 1999. Dispõe sobre o Sistema de Seguridade Social dos Servidores do Município de Curitiba, altera a denominação e modifica a estrutura e atribuições do Instituto de Previdência e Assistência dos Servidores do Município de Curitiba - IPMC, e dá outras providências.

${ }^{63}$ CURITIBA. Lei no 9.712, de 23 de novembro de 1999. Altera dispositivos da Lei n 9626/99 que "dispõe sobre o Sistema de Seguridade Social dos Servidores Municipais de Curitiba, altera a denominação e modifica a estrutura e atribuições do Instituto de Previdência e Assistência dos Servidores do Município de Curitiba IPMC", acrescenta artigo e dá outras providências. 
alíneas "b" e "d", Lei n 9 9626/99). No contrato de gestão ${ }^{64}$ está estabelecido que as metas e os indicadores de desempenho estão no seu anexo I.

Art. 46. Competirá à Secretaria Municipal de Recursos Humanos, em relação ao ICS:

Parágrafo Único. Preservada a autonomia gerencial, patrimonial, financeira e orçamentária do ICS, o Contrato de Gestão, elaborado de comum acordo entre as partes, terá por objeto:

a) a fixação de metas para a realização de suas finalidades;

b) ...

c) a avaliação de desempenho da Entidade, com aferição de sua eficiência... (sem grifo no original)

O parágrafo único do artigo 47 da mesma lei expressa que o prefeito municipal indicará o diretor presidente e os demais diretores do ICS.

Art. 47. A estrutura diretiva do ICS compreenderá:

Parágrafo Único. O Diretor Presidente e os demais Diretores do ICS serão indicados pelo Prefeito Municipal e ratificados pelo Conselho de Administração.

O Conselho de Administração apresenta sete membros (art. 48), quatro são indicados pelo poder executivo municipal, três pelo prefeito e um pelo secretário de recursos humanos.

Em relação às receitas do Instituto Curitiba de Saúde, o artigo 55 da Lei $n^{\circ}$ 9.626/99 estabelece, entre outras: dotações municipais (inciso II). A prefeitura repassa mensalmente para o instituto o equivalente a $3,14 \%$ dos vencimentos dos servidores. ${ }^{65}$

Observa-se também que o ICS recebeu patrimônio do antigo Instituto de Previdência e Assistência dos Servidores do Município de Curitiba (autarquia), bem como do Município de Curitiba (art. 54, incs. I e II, da Lei $\mathrm{n}^{\circ}$ 9.626/99). O artigo 75, da mesma lei, aponta a responsabilidade solidária do município para com o ICS.

\footnotetext{
${ }^{64}$ CURITIBA. Contrato de Gestão n 012.260 que firmam entre si o Município de Curitiba e o Instituto Curitiba de Saúde em 30 de dezembro de 1999.

${ }^{65}$ Artigos 13 e 60 da Lei Municipal n 9626/1999.
} 
Art. 75. O Município é solidariamente responsável:

I - no caso de inadimplência da Entidade devedora:

a) com o IPMC, ${ }^{66}$ pelo pagamento dos benefícios a que fazem jus os servidores públicos, dependentes e pensionistas;

b) com o ICS, pela manutenção e prestação dos serviços médicos, hospitalares e afins, assegurados pelos programas a cargo dessa Entidade;

II - com o ICS, perante os prestadores de serviços, na hipótese de mora durante 02 (dois) meses consecutivos, pelas obrigações de que trata o art. $74 .{ }^{67}$

$\S 1^{\circ}$. Sempre que as contribuições repassadas às Entidades forem insuficientes para cobrir as despesas de que trata o presente artigo, a Prefeitura Municipal fará o aporte, em favor das mesmas, dos recursos adicionais necessários, no prazo do art. 72, I, ${ }^{68}$ desta lei. (parágrafo modificado pela Lei n ${ }^{\circ} 9712 / 99$ )

$\S 2^{\circ}$. No tocante às demais obrigações das Entidades a responsabilidade do Município é subsidiária.

No artigo 77 está registrada a isenção dos tributos municipais para as entidades de seguridade social de Curitiba, ou seja, IPMC e o ICS.

Em relação a recursos humanos constatou-se que o Instituto Curitiba de Saúde contava em 2005 com 214 servidores públicos municipais cedidos (médicos, cirurgiões-dentistas, enfermeiros, técnicos e auxiliares), que prestaram concurso público para prestar assistência a toda população de Curitiba, mas atendiam apenas ao segmento de servidores públicos municipais. ${ }^{69}$

No mesmo instituto existiu cooperativa de profissionais de saúde que prestava serviços a esse Instituto por cerca de um ano e meio, conforme informação de cirurgiã-dentista que atuou neste instituto. ${ }^{70}$ Entretanto, os cooperados e os servidores municipais estatutários cedidos ou da autarquia (antigo IPMC) respondiam à mesma chefia do ICS.

Recorda-se que no antigo IPMC, quando este prestava serviços de saúde, o ingresso na autarquia de médicos, cirurgiões-dentistas e outras

\footnotetext{
${ }^{66}$ O IPMC é o Instituto de Previdência dos Servidores do Município de Curitiba. É de natureza autárquica (art. 15 da Lei no 9626/99). Atua no gerenciamento do sistema previdenciário dos servidores municipais de Curitiba. Anteriormente ele também prestava serviços de saúde, função atualmente exercida pelo ICS-Ctba. Chamava-se Instituto de Previdência e Assistência dos Servidores do Município de Curitiba, e apresentava a mesma sigla IPMC.

${ }^{67}$ Art. 74. O Município, suas autarquias e fundações são responsáveis diretas e exclusivas em face do Sistema de Seguridade e de suas Entidades pelo pagamento de suas contribuições, e pelo repasse daquelas dos servidores ativos e dos pensionistas.

${ }^{68}$ Art. 72. É obrigação da Prefeitura Municipal, da Câmara Municipal, das Autarquias e Fundações para com as Entidades:

I - efetuar, até o $5^{\circ}$ (quinto) dia útil do mês subseqüente ao de competência, a transferência das contribuições e aportes mensais sob sua responsabilidade. (redação Lei nº 9712/99).

${ }^{69}$ CURITIBA. Prefeitura. Resposta do Gabinete do Prefeito à Câmara Municipal de Curitiba. 02 jun. 2005.

70 W. Comunicação pessoal.
} 
profissões, era por meio de concurso público. Atualmente, predomina a indicação política, conforme relato de ex-cirurgiã-dentista, que atuou três anos no ICS. ${ }^{71}$ Em outro depoimento de cirurgião-dentista, ${ }^{72}$ que atualmente trabalha neste serviço social autônomo, ele próprio reconhece a indicação para este instituto por intermédio de um vereador de Curitiba. Observou também que a contratação não é realizada diretamente pelo ICS, mas por uma outra entidade: a Irmandade Santa Casa de Misericórdia de Curitiba. Isto também foi constatado no termo de rescisão do contrato de trabalho de V. W.

Entendemos que não é possível conceber autonomia de uma organização quando há indicação, de cunho político de sua diretoria, recebimento de dotação orçamentária, responsabilidade solidária e subsidiária da Prefeitura de Curitiba e duzentos e quatorze servidores públicos cedidos, como é o caso do Instituto Curitiba de Saúde. Desperta a atenção, também, o parágrafo primeiro do artigo 75 que estabelece que sempre as contribuições forem insuficientes para cobrir despesas, o município fará o aporte dos recursos adicionais necessários.

Fica evidente a dependência dessa organização da Prefeitura de Curitiba. Parece ser mais adequada, tendo em vista suas atividades e sua relação financeira e administrativa com a prefeitura, a figura de autarquia, tal como é o IPMC, que atualmente exerce suas atividades somente na área previdência, mas antes da criação do Instituto Curitiba de Saúde, também prestava serviços de saúde. Neste sentido é a proposta do Sindicato dos Servidores do Magistério Municipal de Curitiba (SISMMAC).

Alteração da Lei do sistema de seguridade (IPMC e ICS), criando conselhos tripartites e transformando o ICS em autarquia; ${ }^{73}$

Na Lei Municipal que institui o Instituto Curitiba de Saúde há previsão de avaliação de seu desempenho, bem como a aferição de eficiência. Entretanto, tivemos dificuldade em obter acesso a informações deste Instituto. Não podemos afirmar se isto vem acontecendo e de que maneira.

No Instituto Curitiba de Saúde há indícios do predomínio de indicações de cunho político, por exemplo, para contratação de cirurgiõesdentistas, e também causa estranheza a contratação de funcionários por

71 W. Comunicação pessoal.

72 L. Comunicação pessoal.

73 CURITIBA. Sindicato dos Servidores do Magistério Municipal de Curitiba. 
terceiros, como a Irmandade Santa Casa de Misericórdia de Curitiba e anteriormente o funcionamento de Cooperativa de Profissionais de Saúde dentro do ICS.

Persistindo a figura de serviço social autônomo do ICS, sugerimos que ele observe as orientações do Tribunal de Contas do Estado: procedimento licitatório conforme a Lei no 8.666/93, prestação de contas a este Tribunal e a contratação de recursos humanos por meio de concurso público ou de teste seletivo.

\section{Considerações finais}

Não há estudos, até o momento, demonstrando maior eficiência dos serviços sociais autônomos. Frisa-se que a eficiência, por si só, não permite uma adequada avaliação do gestor público. Peter Drucker ${ }^{74}$ sugere a utilização conjunta de critérios de eficiência e de eficácia. Mesmos estes apresentam dificuldades, como alerta Luciano Parejo Alfonso, ${ }^{75}$ considerando as limitações deles, bem como as incertezas, as especificidades e as externalidades do setor público.

Os serviços sociais autônomos analisados, em nosso entendimento, não estão inseridos num contexto de reforma administrativa no Estado do Paraná ou no Município de Curitiba. Estas entidades parecem ser utilizadas especialmente para possibilitar maior agilidade e flexibilidade, bem como para "fugir" da alegada rigidez do direito administrativo. O Governo do Estado da época, inicialmente, resistiu à obrigatoriedade de prestação de contas ao Tribunal de Contas do Paraná e de realização de licitação e de concursos públicos nos serviços sociais autônomos. O Instituto Curitiba de Saúde vinculado ao município de Curitiba, somente a partir de 2005 passou a prestar contas ao Tribunal de Contas do Estado.

A utilização de palavras e conceitos como eficiência e eficácia, inclusive nas metas e contratos de gestão das organizações analisadas, parece ser mais um recurso discursivo, já que algumas metas são de difícil mensuração ou genéricas e não foram observadas avaliações sistemáticas sobre estas entidades.

Neste trabalho, analisando a legislação, os estatutos, os contratos de gestão dos serviços sociais autônomos parece muito difícil estabelecer uma avaliação sobre maior ou menor eficiência e eficácia dos mesmos. Frisa-se

\footnotetext{
74 DRUCKER. Managing for results.

75 ALFONSO. Eficacia y Administración: Tres estudios.
} 
que o mero repasse de atividades para estas instituições não garante, por si só, maior eficiência na prestação de serviços. Esta delegação de atividades para serviços sociais autônomos pode trazer, e de fato traz, maior flexibilidade e agilidade. Todavia, esta maior liberdade, dependendo da forma que for utilizada, pode propiciar o incremento do patrimonialismo.

Sugere-se que os serviços sociais autônomos, nos casos estudados, financiados e controlados majotariamente pelo Estado ou Município, sigam os preceitos básicos do direito administrativo: licitação para a aquisição de produtos, serviços e obras, concurso ou teste seletivo público para contratação de pessoal e prestação de contas ao Tribunal de Contas do Estado do Paraná. Esta, inclusive, tem sido, há algum tempo, a orientação deste Tribunal acerca dos Serviços Sociais Autônomos no Paraná. Recomenda-se também a alteração do termo "autônomo" para serviços sociais que dependem da Administração pública. É importante ressaltar, que pelo menos desde 2003, os serviços sociais autônomos vinculados ao Estado do Paraná têm seguido a Lei de Licitações $\mathrm{n}^{\circ}$ 8.666/93 na compra e aquisição de serviços, produtos e obras.

O processo licitatório simplificado ou regulamento próprio de licitação previstos originalmente em alguns serviços sociais autônomos do Sistema " $\mathrm{S}$ " devem ser vistos com precaução. A utilização deste mecanismo no Paranacidade de 1996 até 2002, no qual se previa a dispensa de licitação para valores até trinta mil reais, é altamente questionável e foi motivo de severas críticas no Relatório Final da Comissão Parlamentar de Inquérito SEDU/Paranacidade.

A cessão de servidores públicos estaduais ou municipais, se houver, deve ser em caráter excepcional e limitada a determinado número e por período determinado.

\title{
Autonomous Social Services and Brazilian Public Administration
}

\begin{abstract}
The purpose of this paper is to analyse autonomous social services. Following an evaluation of the organizations that provide these services in the state of Paraná and the municipality of Curitiba, it is possible to state that their creation does not take place within a context of administrative reform, but rather they are more an attempt to achieve greater agility and flexibility and to "avoid" the alleged rigidity of classical administrative law. The use of management model terms such as: efficiency, effectiveness, agility, results and performance; does not necessarily reflect greater concern about the improved performance of public administration, given that the targets contained in the respective management contracts are often excessively generic. No consistent evaluations of increased efficiency and effectiveness
\end{abstract}


were observed. We suggest that autonomous social services, when controlled directly or indirectly by the State, by means of the indication of the majority of their directors or by means of their actions being financed principally with public resources, obey and comply with administrative law, especially with regard to procurement procedures, the public selection process for hiring staff and the rendering of accounts to the State Audit Court.

Key words: Autonomous social services. Efficiency. Effectiveness and evaluation.

\section{Referências}

ALFONSO, Luciano Parejo. Eficacia y administración: Tres estudios. Madrid: INAP - BOE, 1995.

BANDEIRA DE MELLO, C. A. Curso de direito administrativo. 12. ed. São Paulo: Malheiros, 2000 .

BRASIL. Supremo Tribunal Federal, Agravo Regimental no Agravo de Instrumento no 349.477-1, PARANÁ, Relator: Ministro Celso Mello. 11 fev. 2003. DJ, 28 fev. 2003.

BRASIL. Tribunal de Contas da União. Decisão n 907/1997. Ministro Relator Lincoln Magalhães da Rocha. Diário Oficial da União, 26 dez. 1997.

COSTALDELLO, Angela Cassia. Parecer no 14349/00. Protocolo n ${ }^{\circ} 83007 / 00$. Tribunal de Contas do Estado do Paraná, 2002.

CURITIBA. Contrato de Gestão no 012.260 que firmam entre si o Município de Curitiba e o Instituto Curitiba de Saúde em 30 de dezembro de 1999.

CURITIBA. Lei no 9.712, de 23 de novembro de 1999. Altera dispositivos da Lei no 9626/ 99 que "dispõe sobre o Sistema de Seguridade Social dos Servidores Municipais de Curitiba, altera a denominação e modifica a estrutura e atribuições do Instituto de Previdência e Assistência dos Servidores do Município de Curitiba - IPMC”, acrescenta artigo e dá outras providências.

CURITIBA. Lei no 9626 de 8 de julho de 1999. Dispõe sobre o Sistema de Seguridade Social dos Servidores do Município de Curitiba, altera a denominação e modifica a estrutura e atribuições do Instituto de Previdência e Assistência dos Servidores do Município de Curitiba - IPMC, e dá outras providências.

CURITIBA. Prefeitura. Resposta do Gabinete do Prefeito à Câmara Municipal de Curitiba, 02 jun. 2005.

CURITIBA. Sindicato dos Servidores do Magistério Municipal de Curitiba.

DI PIETRO, M. S. Z. Direito administrativo. 14. ed. São Paulo: Atlas, 2002.

DI PIETRO, M. S. Z. Parcerias na administração pública: concessão, permissão, franquia, terceirização e outras formas. 4. ed. São Paulo: Atlas, 2002.

DONATTI, Leandro. Informe Folha: paranacidade. Folha de Londrina, p. 3, 20 nov. 2003.

DRUCKER, P. Managing for results. Nova Iorque: Harper \& Row, 1964.

FERREIRA, Sérgio de Andrea. Estudo jurídico sobre a natureza da Paraprevidência. Revista de Previdência Funcional, ano 1, n. 0, p. 96-121, 2001. 
GALINDO, R. W. Governo Lerner gasta $94 \%$ a mais para manter 25 mil cargos a menos. Gazeta do Povo, Curitiba, p. 3, 26 maio 2002.

GALVÃO, Maria Cristina Costa Pinto (Coord.). Novas formas de gestão dos serviços públicos: a relação público-privada. São Paulo: FUNDAP, 1997.

GRAU, Eros Roberto. Parecer Paraná Tecnologia, 2001. 21 p.

JUSTEN FILHO, Marçal. Comentários à lei de licitações e contratos administrativos. 10. ed. São Paulo: Dialética, 2004.

L. N., J. Comunicação Pessoal, 2006.

MEIRELlES, H. L. Direito administrativo brasileiro. 22. ed. São Paulo: Malheiros, 1997.

MODESTO, Paulo. Reforma do Estado e formas de prestação de serviços. In: SUNDFELD, Carlos Ari (Coord.). Parcerias público-privadas. São Paulo: Malheiros, 2005. p. 433-486.

MOREIRA NETO, Diogo de Figueiredo. Natureza jurídica dos serviços sociais autônomos. Revista Direito Administrativo, 207, p. 79-94, jan./mar. 1997.

PARANÁ. Contrato de gestão que entre si celebram o Estado do Paraná e o Serviço Social Autônomo.

PARANÁ. Estatuto do Serviço Social Autônomo Paranacidade. DOE, n. 5.631, p. 14, 02 dez.1999.

PARANÁ. Estatuto do Serviço Social Autônomo PARANACIDADE. Publicado em DOE, n. 5.631, p 14, 2 dez.1999. PARANÁ. CPI SEDU/PARANACIDADE - Relatório Final. 10 nov. 2003.

PARANÁ. Lei n 12.398, de 30 de dezembro de 1998. Cria o Sistema de Seguridade Funcional do Estado do Paraná, transforma o Instituto de Previdência e Assistência aos Servidores do Estado do Paraná - IPE em Serviço Social Autônomo, denominado PARANAPREVIDÊNCIA, e dá outras providências.

PARANÁ. Lei n 12.651, de 23 de julho de 1999. Altera os dispositivos que especifica da Lei $n^{\circ} 11498$, de 30 de julho de 1996, que institui o PARANACIDADE.

PARANÁ. Lei $\mathrm{n}^{\circ}$ 11.498, de 30 de julho de 1996. Institui o PARANACIDADE, pessoa jurídica de direito privado e adota outras providências.

PARANÁ. Lei no 12.215 , de 10 de julho de 1998. Institui o ECOPARANA, pessoa jurídica de direito privado, sob a modalidade de serviço social autônomo, vinculando-a por cooperação, à Secretaria de Estado do Esporte e do Turismo - SEET.

PARANÁ. Lei no 12.966 , de 25 de outubro de 2000. Altera a redação dos dispositivos que especifica, das Leis $\mathrm{n}^{\circ} \mathrm{s} 11.498 / 96,11.970 / 97$ e 12.215/98, através das quais foram instituídos, respectivamente, o PARANACIDADE, PARANAEDUCAÇÃO e ECOPARANÁ.

PARANÁ. Lei no 15.123 , de 18 de maio de 2006. Dá nova redação nos dispositivos que específica da Lei no 12.020 de 09 de janeiro de 1998, que criou o FUNDO PARANÁ.

PARANÁ. Lei $n^{\circ}$ 8.917, de 15 de dezembro de 1988. Institui o Fundo Estadual de Desenvolvimento Urbano e adota outras providências.

PARANÁ. Projeto de Lei Estadual no 02/2001 (Justificativa). Institui o Sistema de Assistência à Saúde aos servidores públicos ativos e inativos do Estado do PR. 
PARANÁ. Projeto de Lei no 060/2006 (Mensagem nº 013/06). Institui o Serviço Social Autônomo PARANACIDADE e convalida os atos praticados com base na Lei Estadual $\mathrm{n}^{\circ}$ 11.498, de 30.07.1996 alterada pelas Leis Estaduais $\mathrm{n}^{\circ} \mathrm{s} 12.651$, de 23.09.1999, 12.966, de 25.10.2000 e 14.045, de 05.05.2003.

PARANÁ. Termo aditivo ao contrato de gestão celebrado entre o Estado do Paraná e a PARANAPREVIDÊNCIA. Diário Oficial do Estado, Curitiba, 29 ago. 2002.

PARANÁ. Termo de contrato de gestão que celebram o Estado do Paraná e a PARANA PREVIDÊNCIA, Curitiba, 27 maio 1999.

PARANÁ. Tribunal de Contas. Resolução no 7150/99. Relator: Rafael Iatauro. 1 $^{\circ}$ set. 1999.

PARANÁ. Tribunal de Contas. Resolução no 946/02. Relator: Heinz Georg Herwig. 02 maio 2002.

PARANACIDADE. Curitiba, 23 out. 1996.

ROCHA, S. L. F. Terceiro setor. São Paulo: Malheiros, 2003.

SANTOS, Caroline Lopes. Comunicação pessoal, 2006.

SCAFF, F. F. Contrato de gestão, serviços sociais autônomos e intervenção do Estado. Revista Direito Administrativo, 225, p. 273-297, jul./set. 2001.

SEIXAS, Paulo Henrique D’Ângelo. As organizações sociais de saúde em São Paulo, 19982002: uma visão institucional. São Paulo, 2003. 192 f. Dissertação (Mestrado em Administração) - Escola de Administração de Empresas de São Paulo, Fundação Getúlio Vargas.

SILVA, Antonio Toledo. Comunicação pessoal, 2006.

W., V. Comunicação pessoal, 2006.

Informação bibliográfica deste texto, conforme a NBR 6023:2002 da Associação Brasileira de Normas Técnicas (ABNT):

ALCÂNTARA, Christian Mendez. Serviços sociais autônomos e a Administração pública brasileira. A\&C - Revista de Direito Administrativo \& Constitucional, Belo Horizonte, ano 9, n. 37, p. 175-199, jul./set. 2009.

Recebido em: 29.05.09

Aprovado em: 13.08 .09 